\title{
Altruism, labor supply and redistributive neutrality
}

\section{Ana Fernandes}

Received: 26 January 2004 / Accepted: 10 June 2008 /

Published online: 21 May 2010

(C) Springer-Verlag 2010

\begin{abstract}
This paper presents a model of familial altruism in which labor supply is chosen endogenously. The model is used to address the predictions of Ricardian Equivalence, both theoretical and empirical. It is argued that, to the extent that income variation in the data comes mostly from wage and effort changes, the empirical tests of neutrality are misspecified. Numerical estimates suggest that quantitatively important deviations from neutrality may be at work.
\end{abstract}

Keywords Ricardian Equivalence • Endogenous labor supply • Private information

JEL Classification D19 $\cdot \mathrm{D} 64 \cdot \mathrm{D} 82$

\section{Introduction}

The literature on altruism and the family greatly expanded since Becker's (1974) pathbreaking contribution. Family economics has shed light on a number of very diverse economic problems, ranging from the real effects of redistributive intergenerational tax policies to the motives behind the residential choice of young adults, their labor market experiences and human capital accumulation. The cornerstone of this literature typically features a parent

Responsible editor: Alessandro Cigno

A. Fernandes $(\varangle)$

Department of Economics, University of Bern, Schanzeneckstrasse 1, P.O.Box 8573,

3001 Bern, Switzerland

e-mail: ana.fernandes@vwi.unibe.ch

URL: http://anafernandes.name 
with altruistic feelings regarding his offspring and examines the allocation of resources that will materialize through household interaction (Becker 1974). This simple framework suffices to generate a great many number of implications. Those concerning intergenerational transfers (from parent to child and vice-versa) have been the object of very intense scrutiny, especially given their stark implications for fiscal policy first expressed in Barro (1974).

One well-known prediction of the basic altruism model is Ricardian Equivalence, according to which income redistribution within the family will not alter the economic allocation prevailing previous to it. That is, if one dollar were taken from the child's income and given to the parent, in a lump-sum fashion, the latter would simply raise the transfer he was previously giving by exactly one dollar. Thus, nothing would change in the allocation of goods and time prevailing before redistribution. This occurrence has also been labeled as "redistributive neutrality."

Ricardian Equivalence has often been cast in terms of a difference in transfer derivatives: the difference between the derivative of the parental transfer function with respect to parental income minus the derivative with respect to the child's income should equal unity. This result has received enormous empirical scrutiny and been almost unanimously rejected as the estimated difference in transfer derivatives is typically found to be much below unity. ${ }^{1}$

A related body of literature examining the relationship between transfers and labor supply has emerged. For example, Holtz-Eakin et al. (1993) examine the predictions of the "Carnegie conjecture," according to which recipients of large estates would reduce their labor supply, and find the data to be supportive of this assertion. In a similar vein, Joulfaian and Wilhelm (1994) examine the impact of inheritances, actual and expected, on labor supply. They find that labor supply is indeed reduced by inheritances but that the quantitative effect is small. Sloan et al. (2002) propose a model where the child may give the parent money or time. She does not derive utility from leisure, but the opportunity cost of time-her wage - naturally affects her choice across types of transfers. While the wage is an empirically significant variable determining monetary transfers to the parent, it does not statistically affect time transfers. ${ }^{2}$ Dustmann and Micklewright (2001) examine the relationship between parental monetary transfers and the labor supply choices of teenagers. They find that parental

\footnotetext{
${ }^{1}$ The immense literature on micro-models of family transfers has a very good survey in Laferrère and Wolff (2006), which also includes a section on empirical tests. Arrondel and Masson (2006) review the empirical evidence on transfers and compare it with the predictions of altruism, exchange and indirect reciprocity. Perhaps the most well-known empirical piece on the transfer derivative test is Altonji et al. (1997) but the examples are very numerous as can be seen in both surveys. The empirical literature on altruism is briefly discussed in Section 4.

${ }^{2}$ As the authors point out, this result is in line with theory: a higher wage raises the child's opportunity cost of time and this effect counteracts the wealth effect also associated with the higher wage. The net effect is ambiguous from a theoretical point of view, thus not contradicted by an estimated coefficient not significantly different from zero.
} 
transfers reduce the hours worked and the participation rates of children. ${ }^{3}$ This literature thus globally suggests that the allocation of time is not independent of intra-family financial flows. The goal of this paper is to study the joint determination of labor supply and financial transfers within the family.

Naturally, the possibility that intra-family transfers are not altruistically motivated has also received a great deal of attention in the literature. Laferrère and Wolff's survey of transfer motives divides those motives into three broad categories: altruism, exchange and mutuality. In models of exchange, first introduced by Bernheim et al.'s (1985) idea that bequests are payment for the child's attention, and consolidated by Cox (1987), the parent values a service or activity undertaken by the child. Financial transfers to the child may therefore reflect payments in exchange for those services or activities. One well-known possibility is that transfers respond positively to the child's income, as higher income raises the child's opportunity cost from performing the services appreciated by the parent. Further, since income redistribution modifies the bargaining power of household members (and thus the transfers required to pay for the child's services), the exchange model does not deliver a neutrality result. Empirical work by Cox (1987), Cox and Raines (1985) and Cox and Rank (1992) found transfer amounts to depend positively on recipient's income.

The mutuality framework considers the emergence of transfers between generations as the result of a (possibly unwritten) contract or constitution that guides rights and obligations in the extended family. Consolidated by Cigno (1993, 2000), and surveyed in Cigno (2006), the mutuality model postulates a game between the generations of an extended family. Parents find it in their interests to care for their own parents for the game's strategy dictates that "delinquent" progenitors will not receive future assistance from their children. Thus, transfers across generations are set by the requirements of the family's constitution. In principle, transfers amounts are also part of the family's contract and, therefore, should not change with small perturbations of the environment. (Family members will choose to either participate in the transfer contract or not at all.) Again, no presumption of neutrality follows in this environment. Cigno et al. $(1998,2006)$ find empirical evidence supporting mutuality motives in transfer behavior (the probability of providing transfers is greater for those who are credit constrained and transfer amounts are insensitive to donor's income). While not dismissing in any way the predictions of the exchange and mutuality environments, the goal of the present paper is to reexamine the altruism model after introducing the explicit consideration of endogenous labor supply and, in doing so, to reconsider the validity of the associated empirical tests.

This paper proposes a model of familial altruism in which labor supply is chosen endogenously. Two versions of the model are considered: one where the child can adjust hours worked and another where hours are held fixed but

\footnotetext{
${ }^{3}$ Using French panel data, Wolff (2006) finds no significant influence of parental transfers on the labor supply of their children.
} 
the distribution of wages depends on a level of effort that is privately observed by the child. Regarding the endogenous choice of hours, the model illustrates the important distinction that must be made between income sources as far as neutrality results are concerned. While redistribution of nonlabor income in this context is mostly neutral (provided the parent makes transfers to the child before and after it takes place) and redistributive neutrality applies, neutrality is not a well-defined concept when income changes associated with wage variation are considered. In the data, however, one important source of income variation across households comes from wage variation and corresponding adjustment of hours worked. The analysis provides a formula relating the relevant parameter for the redistributive neutrality test with the one presumed to actually emerge from most empirical studies. Illustrative calculations suggest both that the difference is nonnegligible but also that this correction does not rescue the implications of the altruism model: controlling for wages would raise the unity benchmark of the difference in parental transfer derivatives, making it all the more difficult to reconcile the predictions of altruism with the very low empirical estimates for that difference. The difference in transfer derivatives when income variation comes exclusively from wage changes (and the endogenous response of hours) exceeds the Ricardian reference value of unity by $50 \%$ for the benchmark case.

Under the private information version of the model, income variation no longer comes from changes in wages and hours worked but from labor market luck. The distribution of income can however be influenced by the child's privately observed effort, with worse luck being less likely under high effort. Under general assumptions, it is easy to show that the difference in transfer derivatives should be strictly below unity, as found in the data. The reason for this is the need for the parent to provide incentives for the exertion of high effort on the part of the child: the parent will reward high income realizations relatively more than low realizations and move away from the typical purely compensatory role of an altruistic parent under perfect information. ${ }^{4}$ To assess the relevance and plausibility of private information, the counterfactual mean income level associated with low effort is estimated. Calculations in the benchmark case place the child's mean income under low effort level at $84 \%$ of mean income under high effort, and the percentual income reduction could reach $66 \%$ of mean income attained under high effort for some parameter values. Further, under private information it is possible to obtain a positive response of parental transfers to the child's income, a feature driven by the relative likelihood that certain income values would have been the result of high versus low effort.

The empirical estimates of transfer functions that are used to test the altruism model would arguably correspond to an estimate of an average transfer

\footnotetext{
${ }^{4} \mathrm{McGarry}$ (2000) is another example where neutrality breaks down due to the informational content of different income observations. In her model, the child's current income provides information regarding her future income. Different current income realizations therefore imply a shift in expectations regarding future income and this causes neutrality to fail.
} 
function prevailing for a representative family. Introspection readily suggests that both forces - endogenous response of hours to wage variation and private information-are at work in the real world. This work shows that we should not expect to encounter, even under only slight deviations from the simplest form of the altruism model, deviations that incorporate realistic dimensions of labor supply, unitary differences in transfer derivatives unless we could control for wages and private information. As results in Sections 2 and 3 show, this is not evidence that Ricardian Equivalence does not hold since testing that result would require lump-sum income redistribution across generations, a very different source of income variation compared to the cross-section income changes that can be recovered from micro data. Our quantitative results suggest opposing forces may be at work, with the endogenous response of hours to wages biasing empirical estimates upward and private information biasing results in the opposite direction.

The paper proceeds as follows. Section 2 presents the model of labor supply with complete information. Section 3 addresses the private information case. The empirical literature is discussed in Section 4, where numerical results illustrating the results in the two previous sections are also presented. Section 5 concludes.

\section{The effort-enlarged Barro-Becker model}

In this section, I extend the benchmark Barro-Becker model of altruism to include the endogenous choice of labor supply.

\subsection{The model}

Consider a family formed of an altruistic parent, $p$, and a selfish child, $c$. For simplicity, it is assumed that only the child works. Let the constant $\lambda$ take values in $[0.5,1]$. Given a consumption pair $\left(c_{p}, c_{c}\right)$, and the child's effort $e$, the parent's total utility $U_{p}$ is:

$$
U_{p}=\lambda U\left(c_{p}\right)+(1-\lambda) u\left(c_{c}, 1-e\right) .
$$

The direct utility functions $U(\cdot)$ and $u(\cdot)$ are $C^{2}$ and satisfy Inada conditions. The parent's total utility $U_{p}$ is a weighted average of his direct utility from consumption, $U(\cdot)$, and the child's total utility, $u(\cdot) .^{5}$ Both family members enjoy consumption while the child dislikes effort.

\footnotetext{
${ }^{5}$ The restriction $\lambda \in[0.5,1]$ arises naturally if we interpret the parent's utility from consumption as

$$
U\left(c_{p}\right) \equiv u\left(c_{p}, 1-e_{p}\right),
$$

with $e_{p}$ set to a constant (possibly zero). The values of $\lambda$ now reflect a partially altruistic parent, one who loves himself more than his child. Though this is the utility representation we favor, the results would hold for any parental utility function $U_{p}(\cdot)$ with the general properties outlined in the text.
} 
The parent receives exogenous income $I_{p} \in \mathbb{R}_{+}$, whereas the child's total endowment is the sum of the exogenous component $I_{c}$ and the labor payments $w e$, with $\left(I_{c}, w\right) \in \mathbb{R}_{+}^{2}$. Given $I_{p}, I_{c}$ and the market wage $w$, the parent chooses a nonnegative transfer to the child, $T$, as well as the child's working hours, $e$. For simplicity, it will be assumed throughout that income and wages are such that optimal effort is interior.

The child's consumption is then:

$$
c_{c}=I_{c}+w e+T,
$$

while the parent consumes

$$
c_{p}=I_{p}-T .
$$

Optimal transfers and working hours solve ${ }^{6}$

$$
\max _{T \geq 0, e \in[0,1]} \lambda U\left(I_{p}-T\right)+(1-\lambda) u\left(I_{c}+w e+T, 1-e\right) .
$$

First-order conditions are:

$$
\lambda U^{\prime}\left(I_{p}-T\right) \geq(1-\lambda) u_{1}\left(I_{c}+w e+T, 1-e\right),
$$

which holds at equality whenever transfers are strictly positive, and

$$
u_{1}\left(I_{c}+w e+T, 1-e\right) w=u_{2}\left(I_{c}+w e+T, 1-e\right) .
$$

\subsection{Results}

I will first consider the redistributive neutrality experiment. In the spirit of Barro (1974), this experiment amounts to an exogenous relabelling of income in which some quantity $\delta$ is taken from one generation's income and added to the income of the other generation, for example by means of governmental intervention. In what follows, I will consider taking one dollar from the child's (nonlabor) income and adding it to the parent's. The question asked under this experiment is then "What would the parental transfer be if the parent knew that, when the triple $\left(I_{p}, I_{c}, w\right)$ is realized, one dollar of nonlabor income will be redistributed in the way just described?" Transfers will neutralize income redistribution if the transfer after income redistribution corresponds to an increment of exactly one dollar over the no-redistribution amount.

Let $T\left(I_{p}, I_{c}, w\right)$ denote the optimal transfer function provided by the parent in the absence of redistribution, and let $\tilde{T}\left(I_{p}, I_{c}, w\right)$ denote the corresponding schedule when redistribution takes place. Similarly, let $\tilde{e}\left(I_{p}, I_{c}, w\right)$

\footnotetext{
${ }^{6}$ In the spirit of the Barro-Becker tradition, the effort-enlarged model presented here has all the decision making ability centralized in the parent. Since the child is selfish, it would be desirable to allow the child to select effort and to model the interaction between family members as a game. In Fernandes (2000), I model the interaction between parent and child as a noncooperative static game. It is shown that the unique Nash-equilibrium of that game replicates exactly the optimal parental choices of the current model. This is so since the parent cares for the child in a nondistortionary way: conditional on a transfer amount, parent and child would agree on the optimal amount of hours the child should work.
} 
and $e\left(I_{p}, I_{c}, w\right)$ denote the effort choices with and without redistribution, respectively. Notation generalizes for consumption. Transfers are neutral if $\tilde{T}\left(I_{p}, I_{c}, w\right)=T\left(I_{p}, I_{c}, w\right)+1$.

The neutrality experiment does not necessarily correspond to verifying how the initial transfer menu $T(\cdot)$ responds under two different income pairs, $\left(I_{p}, I_{c}\right)$ and $\left(I_{p}+1, I_{c}-1\right)$. As will be made clear below (see Section 3$)$, if the family operates under an asymmetric information environment, for example, the two experiments generally yield different results. The source of this distinction hinges on the fact that redistribution is an exogenous phenomenon: transfers possibly adjust to it but family members know which income values were initially in place. The evaluation of the initial transfer menu under different income values entails a possibly different scenario, if family members perceive alternative endowment points as different. This will be the case when the child's income depends in a nondeterministic way on her privately observed effort: income draws are informative about the child's diligence.

Proposition 1 (Ricardian Equivalence under Complete Information) For $\left(I_{p}, I_{c}, w\right)$ triples such that $T\left(I_{p}, I_{c}, w\right)>0, \tilde{T}\left(I_{p}, I_{c}, w\right)=T\left(I_{p}, I_{c}, w\right)+1$, $\tilde{e}\left(I_{p}, I_{c}, w\right)=e\left(I_{p}, I_{c}, w\right)$.

Proposition 1 states that transfers neutralize income redistribution. The proof follows from verifying that $\tilde{T}$ and $\tilde{e}$ solve the system of first-order conditions of the parent's problem, Eqs. 5 and 6. Naturally, this implies $\tilde{c}_{c}=c_{c}$ and $\tilde{c}_{p}=c_{p}$. This result obviously generalizes to any nonnegative amount $\delta \leq I_{c}$ redistributed in the way just described.

The following Proposition compares the initial transfer schedule under two different income pairs, $\left(I_{p}+1, I_{c}-1, w\right)$ and $\left(I_{p}, I_{c}, w\right)$. The question answered here is "How does the parental transfer under $\left(I_{p}, I_{c}, w\right)$ compare with the transfer the parent will provide if, in turn, $\left(I_{p}+1, I_{c}-1, w\right)$ occurs?"

Proposition 2 (Transfer Slope under Complete Information) For $\left(I_{p}, I_{c}, w\right)$ triples such that $T\left(I_{p}, I_{c}, w\right)>0, T\left(I_{p}+1, I_{c}-1, w\right)=T\left(I_{p}, I_{c}, w\right)+1$, $e\left(I_{p}+1, I_{c}-1, w\right)=e\left(I_{p}, I_{c}, w\right)$.

The proof is identical to the one of the previous Proposition. This result states that the optimal transfer schedule offsets perturbations of familial income which leave the sum $I_{p}+I_{c}$ constant.

From Propositions 1 and 2, we have that

$$
\tilde{T}\left(I_{p}, I_{c}, w\right)=T\left(I_{p}+1, I_{c}-1, w\right)=T\left(I_{p}, I_{c}, w\right)+1 .
$$

In fact, in the present environment devoid of information asymmetries, the two experiments-comparing $\tilde{T}(\cdot)$ with $T(\cdot)$ and comparing $T\left(I_{p}+1, I_{c}-1, \cdot\right)$ with $T\left(I_{p}, I_{c}, \cdot\right)$-yield the same result. Once again, this is true for any nonnegative income amount $\delta$ redistributed within the family. Using the fact that

$$
T\left(I_{p}+\delta, I_{c}-\delta, w\right)=T\left(I_{p}, I_{c}, w\right)+\delta
$$


holds for all $\delta$, and letting $\delta$ become arbitrarily small, the result of the comparison of $T$ under different income draws can be summarized using "local" notation by saying

$$
T_{1}-T_{2}=1 \text { and } e_{1}=e_{2},
$$

thus allowing us to label Proposition 2 in terms of the "slope" of the transfer function.

It should be clear that Ricardian Equivalence results hold when redistribution is carried out in a lump-sum fashion. Ricardian Equivalence does not offer any quantitative prediction for the difference in transfer derivatives should income changes be associated with variation in wages and the corresponding adjustment of hours worked. Providing a quantitative benchmark for the difference $T_{1}-T_{2}$ under the assumption that income aggregates involving labor income have been used in empirical work is the goal of Section 4.1. All parameter configurations considered in that section show that $T_{1}-T_{2}$ exceeds unity when the variation in the child's resources comes mostly from labor income.

We now proceed to the environment with private information.

\section{Private information}

In this section, I assume that the child's effort is privately observed and examine the implications of asymmetric information for the behavior of transfers (see Fernandes (1999) for further details). Other models of the family under asymmetric information include Chami $(1996,1998)$. This work deviates from the existing literature by focussing on the implications of private information for transfer behavior, with particular emphasis on the consequences of income redistribution within the family. ${ }^{7}$

\subsection{The model}

In the current scenario, parent and child play a sequential game as follows. The parent's income $I_{p} \in \mathbb{R}_{+}$is now assumed to be random and distributed

\footnotetext{
${ }^{7}$ Chami (1996) argues that, when the child's effort is privately observed, the parent will be able to induce a higher level of effort from the child if he is able to precommit to a transfer amount as opposed to deciding on a transfer to the child after effort is undertaken. His result thus provides conditions under which Hirshleifer's (1977) assertion that the parent must act after the child's effort is implemented in order to prevent her from shirking-or acting "rotten"-is overturned; it is driven by the fact that the parent can no longer observe the child's effort. In his (1998) piece, Chami again examines the implications of parental transfers and transfer regimes for the intensity of labor supply. The analysis considers a large number of alternative scenarios which include private information and/or merit goods. Chami does not address the question of interest here, namely the effect of private information on the properties of transfers regarding income redistribution and, further, how these results compare with empirical estimates. Gatti (1997) considers a model of bequests under private information and examines how different transfer regimes—related to the parents' ability to commit—affect the utility of the parents.
} 
according to probability density function $\mu(\cdot)$, defined over $\mathbb{R}_{+} \cdot{ }^{8}$ Effort $e$ is understood here as the intensity with which the child works a fixed number of hours. There is randomness in the wage rate she receives, and the distribution of the wage depends on this intensity. Since hours are fixed, there is no real distinction between the wage and her labor income. For notational simplicity, $I_{c}$ denotes the child's total income, drawn from probability density function $f\left(I_{c} ; e\right)$ with support in $\mathbb{R}_{+} .{ }^{9}$ Effort can take values in $E=\left\{e_{H}, e_{L}\right\}, e_{H}>e_{L}$. The density $f\left(I_{c} ; e_{H}\right)$ dominates-in the first-order stochastic sense $-f\left(I_{c} ; e_{L}\right)$; further, $\mu(\cdot)$ and $f(\cdot)$ are statistically independent.

The timing is as follows. The parent moves first and announces a menu of transfers $T\left(I_{p}, I_{c}\right)$, which depends on the future realizations of the endowments. The child then selects a privately observed effort level $e, e \in E$. Income realization $I_{p}$ is drawn from $\mu(\cdot)$ whereas $I_{c}$ is drawn from $f(\cdot ; e)$. Both income realizations are publicly observed. Once the income realizations take place, transfers are implemented according to the announced menu, $T(\cdot)$. Transfers translate into consumption in the obvious way:

$$
c_{p}=I_{p}-T\left(I_{p}, I_{c}\right), \quad c_{c}=I_{c}+T\left(I_{p}, I_{c}\right) .
$$

Momentary utility has the same form as before,

$$
U_{p}=\lambda U\left(c_{p}\right)+(1-\lambda) u\left(c_{c}, 1-e\right),
$$

where $u\left(c_{c}, 1-e_{c}\right)$ represents the child's total utility.

Given the timing of moves, the parent takes into account how the promised menu affects the child's choice of effort. Let $E_{e}$ denote the expectations operator induced by $\mu(\cdot) f(\cdot ; e)$. The parent maximizes his expected utility by choice of the child's effort level $e$ and transfer menu $T\left(I_{p}, I_{c}\right)$, subject to the child being indifferent between exerting $e$ or its complement $e^{c}$ :

$$
\max _{T(\cdot) \geq 0, e \in E} E_{e}\left\{\lambda U\left(c_{p}\right)+(1-\lambda) u\left(c_{c}, 1-e\right)\right\}
$$

subject to

$$
E_{e} u\left(c_{c}, 1-e\right) \geq E_{e^{c}} u\left(c_{c}, 1-e^{c}\right), \text { for } e, e^{c} \in E,
$$

as well as Eq. 7.

\footnotetext{
${ }^{8}$ There is a technical reason for why the parent's income is now stochastic. In Section 2, the income of parent and child was observed before the parental transfer was given or effort exerted. Comparing the parental transfer for different values of the family's income was a straightforward experiment. In this section, the timing of moves-described below-prescribes the parent announcing a transfer menu of payments which are contingent on the future observations of $I_{p}$ and $I_{c}$. If $I_{p}$ is drawn from a degenerate distribution, then the experiment of taking one dollar from the child's income and adding it to the parent's is not well-defined. In other words, the multiplier $\theta$ of the incentive compatibility constraint (9) would be a function of $I_{p}$ as opposed to a function of its distribution, as it is in the current case.

${ }^{9}$ If there is a nonlabor component in the child's earnings, as it was the case in Section 2, it is assumed that the parent knows how much it totals.
} 
Equation 9 is the incentive compatibility condition. I assume that this constraint is binding and also that $e_{H}$ solves the problem stated in Eqs. 8 and 9. Let $\theta$ denote the strictly positive multiplier associated with Eq. 9 .

The optimal transfer menu $T\left(I_{p}, I_{c}\right)$ satisfies the following first-order condition:

$$
-\lambda U^{\prime}\left(c_{p}\right)+u_{1}\left(c_{c}, 1-e_{H}\right)\left[(1-\lambda)+\theta\left(1-\frac{u_{1}\left(c_{c}, 1-e_{L}\right)}{u_{1}\left(c_{c}, 1-e_{H}\right)} \frac{f\left(I_{c} ; e_{L}\right)}{f\left(I_{c} ; e_{H}\right)}\right)\right] \leq 0,
$$

which holds at equality whenever $T$ is strictly positive.

Define $F\left(I_{c}\right) \equiv f\left(I_{c} ; e_{L}\right) / f\left(I_{c} ; e_{H}\right)$, commonly known as the likelihood ratio. Let $U_{1}\left(c_{c}\right)$ stand for the ratio of marginal utilities from consumption associated with different effort levels, $U_{1}\left(c_{c}\right) \equiv u_{1}\left(c_{c}, 1-e_{L}\right) / u_{1}\left(c_{c}, 1-e_{H}\right)$, $U_{1}(\cdot)>0$. When transfers are positive, we may now rewrite the first-order condition as:

$$
\lambda U^{\prime}\left(c_{p}\right)=u_{1}\left(c_{c}, 1-e_{H}\right)\left[(1-\lambda)+\theta\left(1-U_{1}\left(c_{c}\right) F\left(I_{c}\right)\right)\right] .
$$

Inspection of the previous equation shows that, holding other things constant, the child will be rewarded when the odds that a particular realization of $I_{c}$ was obtained under $e_{H}$ are high. In fact, a low value of $F\left(I_{c}\right)$ indicates that the probability of $I_{c}$ being drawn from high effort is large relative to $f\left(I_{c}, e_{L}\right)$. In turn, a low ratio $F\left(I_{c}\right)$ raises the ratio of the parent's marginal utility over the child's.

Regarding the term $U_{1}\left(c_{c}\right)$, for separable utility functions $U_{1}(\cdot)$ is simply a constant (unity). When the child's utility is not separable in consumption and leisure, $U_{1}(\cdot)$ is a marginal utility correcting factor which takes into account how the different effort levels affect the child's marginal utility from consumption. For example, if leisure raises the marginal utility from consumption, then $U_{1}\left(c_{c}\right)>1$. The mentioned complementarity between consumption and leisure will cause the parent not to compensate the child as much for high effort since her marginal utility from consumption is lowered by the child's diligent activity. When $U_{1}(\cdot)>1$, this effect, therefore, goes in the opposite direction of a low ratio $F\left(I_{c}\right)$.

Consider now the redistribution experiment of taking one dollar from the child's income and adding it to the parent's endowment. As in Section 2, the question here is "What would the parent's transfer be if the parent knew that, upon $\left(I_{p}, I_{c}\right)$ taking place, one dollar would be redistributed within the family?" Denote by $\tilde{T}\left(I_{p}, I_{c}\right)$ the new transfer menu under redistribution. The following proposition shows that redistribution is neutral if parents provide positive transfers for all income realizations.

Proposition 3 (Ricardian Equivalence Under Private Information) If the density functions $\mu\left(I_{p}\right), f\left(I_{c} ; e_{H}\right)$ and $f\left(I_{c} ; e_{L}\right)$ are such that $T\left(I_{p}, I_{c}\right)>0$, for all realizations of $\left(I_{p}, I_{c}\right)$, then $\tilde{T}\left(I_{p}, I_{c}\right)=T\left(I_{p}, I_{c}\right)+1$. 
The need to restrict the result to densities such that transfers are always positive can be understood as follows. If that were not the case, income redistribution for realizations $\left(I_{p}, I_{c}\right)$ such that transfers are zero would not be undone by the parent. In turn, given that redistribution changes the consumption allocation for at least some of the income realizations, this would also change the "cost" for the parent of making the initial transfer function incentive compatible. In other words, the multiplier associated with the the incentive compatibility constraint would also change. In being at least partially effective, redistribution is modifying the initial conditions, it is having an effect comparable to a change in $\mu(\cdot)$. It is worth emphasizing, however, that redistribution does not affect the parent's perception of how hard the child works. That is, the ratio $F\left(I_{c}\right)$, which adjusts parental compensation in order to give the child hard working incentives, remains unchanged under the redistribution experiment. This is the key fact underlying neutrality, provided transfers are positive for all $\left(I_{p}, I_{c}\right)$ pairs.

A different question concerns the properties of the initial transfer menu, $T\left(I_{p}, I_{c}\right)$, in the following sense. When comparing two different income pairs, $\left(I_{p}, I_{c}\right)$ and $\left(I_{p}+1, I_{c}-1\right)$, say, is it also the case that transfers fully offset the income changes? Since it is feasible for the parent to increase the transfer from $T\left(I_{p}, I_{c}\right)$ to $T\left(I_{p}, I_{c}\right)+1$, would this be a property of optimal transfers? The answer to this question is "no" and the intuition is as follows. The different income realizations of the child have associated different values of $F(\cdot)$. This causes the parent to perceive $I_{c}$ and $I_{c}-1$ as different, and the insurance/incentives trade-off described above will reward the child relatively more under $I_{c}$, if $F\left(I_{c}\right)$ is lower than $F\left(I_{c}-1\right)$.

By fully differentiating the first-order condition (11) and imposing $d I_{p}=$ $-d I_{c}$, one obtains the slope of the transfer menu across income pairs $\left(I_{p}, I_{c}\right)$ such that $I_{p}+I_{c}$ is constant. The result is:

$$
d T\left(I_{p}, I_{c}\right)=\left(1-\frac{u_{1}\left(c_{c}, 1-e_{H}\right) \theta U_{1}\left(c_{c}\right) F^{\prime}\left(I_{c}\right)}{D}\right)
$$

with $D$, the denominator in the previous expression, given by:

$$
\begin{aligned}
D= & \lambda U^{\prime \prime}\left(c_{p}\right)+u_{11}\left(c_{c}, 1-e_{H}\right)\left[(1-\lambda)+\theta\left(1-U_{1}\left(c_{c}\right)\right) F\left(I_{c}\right)\right] \\
& -u_{1}\left(c_{c}, 1-e_{H}\right) \theta U_{1}^{\prime}\left(c_{c}\right) F\left(I_{c}\right) .
\end{aligned}
$$

As Eq.12 indicates, the "slope" of the transfer menu will generally deviate from unity, the value which would entail a complete offset of the income perturbations. The sign of the ratio in Eq. 12 hinges on the signs of $F^{\prime}(\cdot)$ and $U_{1}^{\prime}(\cdot)$. Having $F^{\prime}(\cdot)<0$, a condition know in the literature as the monotone likelihood ratio property, is a sufficient condition for $f\left(\cdot ; e_{H}\right)$ to first-order 
stochastically dominate $f\left(\cdot ; e_{L}\right) .{ }^{10}$ The derivative of the ratio $U_{1}(\cdot)$ would be zero if $u(c, e)=\log (c)-e$, for example. Having $F^{\prime}(\cdot)<0$ and $U_{1}^{\prime}(\cdot) \geq 0$ is sufficient for $d T\left(I_{p}, I_{c}\right)<1 .{ }^{11}$ This implies that transfers less than fully compensate the child for income losses, even when the family's total income remains constant. This result is summarized in the next Proposition.

Proposition 4 (Transfer Slope under Private Information) If (i) the density functions $\mu\left(I_{p}\right), f\left(I_{c} ; e_{H}\right)$ and $f\left(I_{c} ; e_{L}\right)$ are such that $T\left(I_{p}, I_{c}\right)>0$, for all realizations of $\left(I_{p}, I_{c}\right)$, (ii) the family of densities $f\left(I_{c} ; e\right)$ satisfies the monotone likelihood ratio property, and (iii) $U_{1}^{\prime}(\cdot) \geq 0$, then the difference $T_{1}-T_{2}$ between the derivatives of the transfer function $T\left(I_{p}, I_{c}\right)$ is smaller than unity.

From an algebraic point of view, the transfer slope deviates from unity to the extent that $\theta F^{\prime}\left(I_{c}\right) \neq 0$. The relevance of the factor $F^{\prime}(I) \neq 0$ can be understood as follows. Loosely speaking, when the income perturbation takes place, we are comparing two endowment pairs, $\left(I_{p}, I_{c}\right)$ and $\left(I_{p}+1, I_{c}-1\right)$. The optimal transfer payment, constrained to provide incentives for $e_{H}$ to be exerted, forces transfers to depend on $F\left(I_{c}\right)$. The derivative $F^{\prime}(\cdot)$ reflects the need to adjust the transfer payment as a function of the relative likelihood that low effort was exerted. For example, for $I_{c}$ values such that $F^{\prime}\left(I_{c}\right)<0$, the drop in the child's income will not be fully compensated by the parent $\left(d T\left(I_{p}, I_{c}\right)<1\right)$. The reduction in the child's post-transfer income ensures that her incentives for hard work remain effective.

It is also instructive to decompose the total transfer differential following an increment in $I_{p}$ matched by an equal size reduction in $I_{c}$ in its two parcels: $d T / d I_{p}$ and $d T / d I_{c}$. Since, in the model, there is no private information associated with the donor's income, transfers respond to changes in $I_{p}$ as predicted by altruism: they increase with the donor's income. However, changes in the child's income will deviate from the benchmark of "pure altruism" since the parent must reward higher income in order to make $e_{H}$ more attractive than shirking. One possibility of interest is that of a positive response of transfers to the child's income. That is, could $d T / d I_{c}$ be positive? The sign of $d T / d I_{c}$ is ambiguous from a theoretical point of view and it is conceivable that, for some parameter values and income realizations, the derivative of parental transfers with respect to the child's income were positive: parental transfers

\footnotetext{
${ }^{10}$ If the family of densities $f(\cdot \mid e)$ satisfies the monotone likelihood property, then, for all $I_{c}^{1} \geq I_{c}^{0}$ and $e_{H} \geq e_{L}$,

$$
\frac{f\left(I_{c}^{1} \mid e_{H}\right)}{f\left(I_{c}^{1} \mid e_{L}\right)} \geq \frac{f\left(I_{c}^{0} \mid e_{H}\right)}{f\left(I_{c}^{0} \mid e_{L}\right)} .
$$

That is, the ratio of the probabilities that $I_{c}$ occurs under high and low effort is increasing in $I_{c}$. The ratio of probabilities in the first-order condition, $F\left(I_{c}\right)$, is the reciprocal of that in Eq. 13 , and thus the monotone likelihood ratio property implies that $F(\cdot)$ is decreasing in $I_{c}$.

${ }^{11}$ Note that, from the first-order condition for transfers, Eq. 11, we know that the expression in square brackets in the denominator $D$ is strictly positive when transfers are also strictly positive.
} 
could respond positively to the child's income due to the need of conveying incentives. This possibility also casts the earlier results of Cox and coauthorswho found transfer amounts to vary positively with the recipient's income-in a new light: ${ }^{12}$ although a positive sign of $d T / I_{c}$ is consistent with exchange, it is also consistent with altruism in the presence of private information. In the quantitative exercise of the next section, $d T / d I_{c}$ was in fact found to be positive for all parameter values considered.

Along the same lines, Proposition 4 shows that the difference in transfer derivatives will be less than unity, but it does not restrict its value. Since transfers respond positively to parental income, a very low-and even possibly negative-value for $T_{1}-T_{2}$ would be more likely provided $d T / d I_{c}$ were positive. Another interesting possibility, not ruled out by the model, would be for transfers to respond negatively to the child's income at low values of $I_{c}$, where differences in marginal utilities across family members might dominate over incentives, but to increase with $I_{c}$ above a certain threshold, if the incentives motive started to dominate then. Some authors identified this transfer pattern in the data. (See e.g. Cox et al. (2004), with data from the Phillipines, and Wolff (1998), using French data.) Private information thus suggests multiple paths for reconciling altruism with transfer behavior and overturns the assertion in Arrondel and Masson (2006) that "Parental altruism cannot explain noncompensatory gifts or bequests."

Could $\theta$ be zero, so that parent and child preferred the same effort choice? It is definitely a possibility. A binding incentive compatibility constraint depends on the fact that parent and child disagree over the effort choice. This could happen in the current setup since the child's effort choice affects the parent's expected utility via the probability distribution from which $I_{c}$ is drawn. Such disagreement was absent from Section 2 since the child's effort did not affect the child's wage or her nonlabor income.

The question-"What is the slope of the transfer menu across pairs of family income with the property that the sum $I_{p}+I_{c}$ is constant?"-is quite pertinent in view of the interpretation that one may attribute to estimates of transfer functions from panel data. In fact, the data used to estimate transfer functions will typically consist of observations of $\left(I_{p}, I_{c}\right)$ for each family in the panel. Once demographic and taste elements have been controlled for, this empirical exercise corresponds to an estimate of the transfer function $T\left(I_{p}, I_{c}\right)$. As described in Section 4, tests of redistributive neutrality have been performed by comparing estimates of $T_{1}-T_{2}$ with the benchmark value of unity, allegedly implied by the null. As shown above, this procedure does not capture the redistributive neutrality result. Under the light of information asymmetries, it at best provides an estimate of how parental transfers react to information on the child's effort.

In view of the previous discussion, it is not surprising that redistributive neutrality has been overwhelmingly rejected in the empirical literature. A

\footnotetext{
${ }^{12}$ See also the results in Jürges (1999).
} 
reference value for the difference in transfer derivatives, obtained by estimating a transfer function using panel data, can be found in Altonji et al. (1997). The estimates produced by that study indicate that $T_{1}-T_{2}$ does not exceed 13 cents, a very small magnitude compared to the expected dollar. ${ }^{13}$

\section{Quantification}

In this section, the results from the empirical literature are analyzed under the light of endogenous labor supply. Two questions are asked here. First, we start from the realization that most empirical studies are not able to identify nonlabor income and rely, instead, on measures that include labor income. This being the case, what would the quantitative implications for redistributive neutrality under perfect information be? Stated differently, if most empirical tests have used measures of labor income in their estimates of $T_{1}-T_{2}$, what should the value of the resulting estimate have been? Should we expect $T_{1}-T_{2}$ to be larger or smaller than unity? And how does the "new" benchmark compare with actual estimates? While the altruism model described in Section 2 has clear predictions for this derivative difference if nonlabor income is used, no prediction is available for $T_{1}-T_{2}$ under income variation arising from wage changes and the corresponding endogenous response in hours worked. To answer this question, we parameterize the utility functions of parent and child with a common functional form, assume standard parameter values and evaluate consumption and transfers at mean sample values reported in empirical studies to come to an estimate of $T_{1}-T_{2}$.

Second, we consider the polar case of the incomplete information model, where all variation in income comes from luck and there is no change in hours worked. We adopt actual estimates of $T_{1}-T_{2}$ from the empirical literature. Having done so, we solve for the mean of the counterfactual income distribution that would have prevailed had the parent not provided incentives for the child to work hard. By comparing it with mean income of the true distribution of earnings, we get a quantitative sense of the relevance of private information.

The functional form chosen for the utility function of the parent (which of course includes the child's) is:

$$
U_{p}=\lambda \frac{c_{p}^{\alpha}}{\alpha}+(1-\lambda)\left[\frac{c_{c}^{\alpha}}{\alpha}+\gamma \frac{(1-e)^{\omega}}{\omega}\right] .
$$

In Section 4.1 on complete information, $e$ will correspond to the fraction of time spent working, whereas in Section 4.2, where incomplete information is considered, it will correspond to the intensity of effort.

\footnotetext{
${ }^{13}$ Other researchers, who also estimate transfer functions (for example McGarry and Schoeni $(1995,1997))$ report—at least heuristically— that the implied difference in transfer derivatives falls far short of the neutrality benchmark.
} 


\subsection{Complete information}

A substantial part of recent empirical work on altruism has devoted attention to the properties of financial and time transfers between parents and their adult children. Some examples of this literature include Altonji et al. $(1996,1997)$, McGarry and Schoeni (1995, 1997), Cox (1987), Cox and Raines (1985) and Cox and Rank (1992).

In Section 2, optimal transfers from parent to child were shown to take the form $T\left(I_{p}, I_{c}, w\right)$, and to verify redistributive neutrality. One possible empirical approach, in order to estimate transfer functions, would be to specify a functional form for the transfer equation, taking into account how demographic factors such as family size and age composition may affect the propensity and amount of transfers. Generalizing the transfer function to depend on the parent's wage,${ }^{14}$ I now use $w_{p}$ to denote the parent's wage and similarly for the child's. One could then write the following empirical equation:

$$
T=\alpha+\beta_{1} I_{p}+\beta_{2} I_{c}+\gamma_{1} w_{p}+\gamma_{2} w_{c}+\delta_{p} X_{p}+\delta_{c} X_{c}+u,
$$

where $X$ denotes a vector of demographic variables and $u$ is a random disturbance assumed to be drawn from a known distribution. In this context, $T$ represents the amount of financial transfers from parents to their children. The parameters in Eq. 15 could then be estimated from data on a cross-section of households. Theory predicts that $\beta_{1}-\beta_{2}=1$-redistributive neutralitywhile no particular numerical value is assigned to the difference $\gamma_{1}-\gamma_{2}$.

The properties of transfers have been analyzed using versions of Eq. 15 of the following form:

$$
T=a+b_{1} I_{p}^{S}+b_{2} I_{c}^{S}+d_{1} X_{p}+d_{2} X_{c}+v,
$$

where the superscript $S$ indicates total income: the sum of labor and nonlabor income. The child's total income, in the notation of Section 2, is then $I_{c}^{S}=$ $I_{c}+w e$. Thorough empirical experimentation has estimated Eq. 16 using several different possibilities for the income variables, including current and permanent income.

In all the work cited here, reference has been made to the redistributive neutrality test. Redistributive neutrality has been interpreted as the statement that the difference between the transfer derivatives with respect to parent and child's income should equal unity. Using the notation of the test equation above, this translates into $b_{1}-b_{2}=1$. As mentioned above, Altonji et al.'s estimates of this difference do not exceed 13 cents.

The Barro-Becker model, enables us to relate the parameter of interest concerning redistributive neutrality, the coefficient $\beta_{2}$ in Eq. 15, with the

\footnotetext{
${ }^{14}$ The model of Section 2 did not consider the choice of parental labor supply. By including the parent's wage in the empirical Eq. 15, I am considering here the more realistic generalization of the model, with parents participating in the labor market and earning wage $w_{p}$.
} 
parameter actually estimated, $b_{2}$, from Eq. 16 . The child's total income relates to labor income as follows:

$$
I_{c}^{S}=I_{c}+w e .
$$

Suppose that the exogenous component of $I_{c}^{S}$ is very small, so that most of the changes in $I_{c}^{S}$ are due to changes in wages and corresponding labor supply adjustment. ${ }^{15}$ Then, changes in $I_{c}^{S}$ relate to changes in the wage rate $w$ as follows:

$$
d I_{c}^{S}=\left[1+\frac{w}{e} \frac{\partial e}{\partial w}\right] e d w .
$$

Let $\eta_{e, w}$ stand for the elasticity of labor supply with respect to changes in the wage. Then, we may rewrite Eq. 17 as follows:

$$
d w=\frac{d I_{c}^{S}}{\left(1+\eta_{e, w}\right) e} .
$$

From the model of Section 2, desired transfers depend on the wage rate as well as on the exogenous income components, $I_{p}$ and $I_{c}$. It can be shown that the derivative of parental transfers with respect to the child's wage takes the form:

$$
\frac{\partial T}{\partial w}=\left[\frac{\partial T}{\partial I_{c}}-\frac{\partial e}{\partial I_{c}} \frac{u_{1}}{\lambda U^{\prime \prime} e}\right] e .
$$

Using Eq. 18, we get:

$$
\frac{\partial T}{\partial I_{c}^{S}}=\left[\frac{\partial T}{\partial I_{c}}-\frac{\partial e}{\partial I_{c}} \frac{u_{1}}{\lambda U^{\prime \prime} e}\right] \frac{1}{\left(1+\eta_{e, w}\right)} .
$$

Leaving aside the implications of using the functional form in Eq. 16 to estimate the transfer function in Eq. 15, one may think of the number given in Eq. 19 as the expression that was actually estimated. ${ }^{16}$ Recall that the redistributive neutrality property applies to the term $\partial T / \partial I_{c}$. In fact, the model of an altruistic parent and his child predicts $\partial T / \partial I_{p}-\partial T / \partial I_{c}=1$. Using the notation of the test equations, we may rewrite Eq. 19 as:

$$
\frac{\partial T}{\partial I_{c}^{S}}=\left[\beta_{2}-\frac{\partial e}{\partial I_{c}} \frac{u_{1}}{\lambda U^{\prime \prime} e}\right] \frac{1}{\left(1+\eta_{e, w}\right)} \simeq b_{2} .
$$

It is worth comparing the actual estimate $b_{2}$ with $\beta_{2}$. The term in brackets is more negative than $\partial T / \partial I_{c}$, from the assumption that leisure is normal. On

\footnotetext{
${ }^{15}$ Whether or not $I_{c}$ is small does not affect the substance of the results presented here, while simplifying the exposition.

${ }^{16}$ The actual estimate, without the assumption that $I_{C}$ is small, would be an weighted average of the coefficient presented in Eq. 19 and $\partial T_{p} / \partial I_{c}$.
} 
the other hand, to the extent that the elasticity of labor supply is positive (negative), this reduces (raises) the absolute magnitude of actual estimates. If the effect of the labor supply elasticity dominates, in the sense of outweighing the effect of the second parcel of Eq. 20, then $b_{2}$ will be strictly smaller than $\beta_{2}$, in absolute value. Since neutrality tests have been performed by computing the difference $\partial T / \partial I_{p}^{S}-\partial T / \partial I_{c}^{S}$, and the estimates of $\partial T / \partial I_{c}^{S}$ have generally been found to be negative, "compressed" estimates of $\partial T / \partial I_{p}^{S}$ and $\partial T / \partial I_{c}^{S}$ due to the dampening effect of the labor supply wage elasticity could help explain the very low value of the "test" results, which have been found to be significantly below unity. Although estimates of male labor supply wage elasticities tend to be negative, female labor supply elasticities are positive and more elastic (see below). The number $\eta_{e, w}$ represents the wage elasticity of the child's household. As such, when head and spouse are present, it will not correspond exactly to any of these estimates but will instead reflect their joint hours' response to wage changes.

The objective of the current section is to provide an estimate of $b_{1}-b_{2}$ and compare it with results from the empirical literature. If the parent has no ability to choose hours worked, $b_{1}$ will coincide with $\beta_{1}$. Since, from a lifecycle point of view, parents are more likely to have stabler jobs relative to their children, this is not an unrealistic approximation. We therefore present results for the difference $\beta_{1}-b_{2}$. The numerical strategy was one of evaluating the main quantities of the model-consumption of parent and child, hours worked, transfers and so on-using mean values from the PSID, as reported in Altonji et al. (1996, Table A2-1). Consumption of parent and child were set to their permanent income values minus (plus) transfers given (received); transfers from parent to child equaled the difference between total transfers to children net of their transfers to parents.

We set $\alpha$ to -1 , corresponding to an elasticity of intertemporal substitution of 0.5 , a common value in the literature. Given the values of $c_{p}, c_{c}$ and $\lambda$, the first-order equation for positive transfers

$$
\lambda c^{\alpha-1}=(1-\lambda) c_{c}^{\alpha-1}
$$

provides an estimate of $\lambda, 0.6234$, within the range of values consistent with partial altruism $(\lambda \in(0.5,1])$.

Total yearly hours worked equal an endowment $H$, minus the hours that the household head spent unemployed as reported in Altonji et al. (1996). The endowment $H$ is set to 3000 , the product of 50 weeks of 40 hours times 1.5; the underlying assumption is that members of the child's household take two weeks of vacation off and the spouse works half-time. ${ }^{17}$ The fraction of time spent working, $e$, is the ratio of the number of hours worked over $H$.

The child's budget constraint reads:

$$
c_{c}=I_{c}+T+w e .
$$

\footnotetext{
${ }^{17}$ Results are virtually insensitive to the choice of $H$.
} 
Thus, the wage $w$ represents the product of the hourly wage times the total time endowment $H$. The hourly wage is computed by dividing permanent earnings by hours worked; $w$ is the product of the hourly wage and the yearly time endowment $H$.

Given $\alpha$, the values of $\omega$ and $\gamma$ are related through the first-order condition for hours:

$$
c_{c}^{\alpha-1} w=\gamma(1-e)^{\omega-1} \Longleftrightarrow \omega=\frac{(\alpha-1) \ln c_{c}+\ln w-\ln \gamma+\ln (1-e)}{\ln (1-e)} .
$$

Parameters $\omega$ and $\gamma$ are found by imposing that the elasticity of labor supply with respect to the wage equal a target number and that Eq. 22 be satisfied. The target value for the wage elasticity of labor supply is 0.1. Blundell et al. (1998) provide estimates of female labor supply ranging from 0.13 to 0.371 (table IV). In Borjas (1996, pp68), the wage elasticity of labor supply for males is negative, -0.1 , whereas that of females is positive, of about 0.2 . The elasticity to use for calibration purposes should be an average across household members. We start with $10 \%$ and later discuss the sensitivity of results to this number.

Table 1 shows the results of the simulations for the benchmark case in the third column $(\lambda=0.62)$. Comparison of the estimates of $\beta_{2}$ with $b_{2}$ shows that the latter is over twice as large as the former in absolute value. The last row of the table provides estimates of the difference between $\beta_{1}$ and $b_{2}$. For the benchmark case, the difference exceeds by $50 \%$ the unity reference value corresponding to redistributive neutrality. It thus appears that failing to consider the endogenous adjustment of hours to wage variation causes the difference in income derivatives to deviate significantly from unity, though not in a way that would help the neutrality hypothesis. In fact, endogenous labor supply leads to an increase in the coefficient of interest of about $50 \%$ in the benchmark case.

The other columns of Table 1 estimate the coefficient of interest with alternative values of $\lambda$, ranging from 0.55 to 0.7 . For $\lambda$ values exceeding 0.7 , no well-defined numerical solution was found (either $\omega$ was estimated above unity, making the utility function convex with respect to leisure, or complex

Table 1 Redistributive neutrality under complete information

\begin{tabular}{llllrr}
\hline$\lambda$ & 0.55 & 0.6 & 0.62 & 0.65 & 0.7 \\
$\gamma\left(\times 10^{4}\right)$ & 0.1236 & 0.1374 & 0.1449 & 0.1541 & 0.1746 \\
$\omega$ & 0.8920 & 0.9231 & 0.9385 & 0.9568 & 0.9932 \\
$\eta_{e, w}^{*}$ & 0.1003 & 0.1003 & 0.1003 & 0.1004 & 0.1007 \\
$\beta_{1}$ & 0.4691 & 0.5532 & 0.6022 & 0.6718 & 0.9133 \\
$\beta_{2}$ & -0.5309 & -0.4468 & -0.3978 & -0.3282 & -0.0867 \\
$b_{2}$ & -0.8221 & -0.8577 & -0.8955 & -0.9722 & -1.4067 \\
$\beta_{1}-b_{2}$ & 1.2912 & 1.4108 & 1.4977 & 1.6440 & 2.3200 \\
\hline
\end{tabular}

Parameter values: $\alpha=-1, H=3000$

${ }^{*} \eta_{e, w}$ is the wage elasticity of labor supply, a target value of the computations 
roots were found for $\gamma$, or both). ${ }^{18}$ We see that, as $\lambda$ increases, so does the difference $\beta_{1}-b_{2}$, a difference which exceeds unity for all cases considered. ${ }^{19}$

Lower values of $\alpha$ (e.g. $\alpha=-1.25)$ deliver similar results. As we raise $\alpha$, however, the difference $\beta_{1}-b_{2}$ declines. Interestingly, for $\alpha=0.5$ (the elasticity of intertemporal substitution equals 2 in this case), the difference $\beta_{1}-b_{2}$ is very close to unity. For this value of $\alpha$, the corresponding value of $\lambda$ that solves Eq. 21 equals 0.53 . For $\lambda$ values ranging from 0.53 to 0.85 , the difference $\beta_{1}-b_{2}$ ranges between 1.08 and 1.17. Just as in the other cases studied, $\beta_{1}-b_{2}$ is increasing in $\lambda$ and exceeds unity for all $\lambda$ values. Thus, there are parameter values under which the endogenous choice of hours does not significantly affect the predicted value of $\beta_{1}-b_{2}$ relative to the unity benchmark corresponding to redistributive neutrality.

The results are sensitive to the target value of the wage-elasticity of labor supply as follows. The difference of interest $-\beta_{1}-b_{2}$-declines as the target value of $\eta_{e, w}$ is lowered toward zero. For example, for $\alpha=-1$ and imposing a target value for $\eta_{e, w}$ of 0.05 , we have that $\beta_{1}-b_{2}$ equals 1.26 , an important reduction from the benchmark value of 1.5 , though still significantly above unity. The reduction of $\beta_{1}-b_{2}$ as $\eta_{e, w}$ is lowered generalizes to all the cases considered. For $\alpha=0.5$, for example, the estimate of $\beta_{1}-b_{2}$ already close to unity when $\eta_{e, w}$ was set to $10 \%$ is further lowered to 1.04 when we target $5 \%$ instead. ${ }^{20}$

The results of this section globally suggest that the omission of endogenous labor supply does not rescue the redistributive neutrality hypothesis, as far as empirical results are concerned: the gap between the empirically estimated transfer derivative difference and the theoretically expected coefficient (quantified above) appears greater than previously thought.

\subsection{Incomplete information}

The results under private information show that the difference $\beta_{1}-\beta_{2}$ should be strictly smaller than unity. The endogenous effort dimension of labor supply

\footnotetext{
${ }^{18}$ Empirical evidence directly targeted at the determinants of well-being and happiness, such as Schwarze and Winkelmann (2005) and Bruhin and Winkelmann (2009), has identified positive and significant effects of the well-being of the child on the parent's. The estimates of the altruism parameter in Schwarze and Winkelmann would imply higher values for $\lambda$, in agreement with the indirect evidence uncovered in Bruhin and Winkelmann. The quantification under private information below considers higher $\lambda$ values.

${ }^{19}$ It may appear surprising that the coefficient $\beta_{1}$ is increasing in $\lambda$, since the greater its value the more selfish the parent. The reason this is the case is the fact that, as $\lambda$ increases, what is being kept constant is the combination of $\gamma$ and $\omega$ values such that $\eta_{e, w}$ equals a target value of 0.1 . If those were kept constant, $\beta_{1}$ would decrease with $\lambda$ (and so would $\beta_{2}$ ).

${ }^{20}$ For negative values of $\eta_{e, w}$, well-defined solutions are only found for negative values of $\alpha$. Further, for these values of $\alpha$, the range of $\lambda$ values for for which solutions exist is usually very high, in particular significantly higher than the value of $\lambda$ that would set the first-order condition of transfers at equality. For example, for $\alpha=-1$ and $\lambda=0.8, \beta_{1}-b_{2}$ equals 1.83 . This difference declines as $\lambda$ increases further. We find the admissible range of values for $\lambda$ implausibly high and therefore disregard these cases.
} 
thus offers a way of reconciling theory and data. To assess the importance of private information, we estimate the mean income associated with the loweffort income distribution, which the child would have earned if she had not exerted effort. First, we disregard the endogenous change in hours and take the model under private information as the "true model." Later in this section, we discuss ways of bringing both models together from a quantitative point of view.

Our strategy is as follows. We take the empirical estimates of $T_{1}-T_{2}$ as given, and set it to 0.13, as reported in Altonji et al. (1997). The model of private information provides an expression for the difference in transfer derivatives in Eq. 12. Beyond parameters of the utility function and consumption values, this equation is a function of the distribution of income under high and low effort. It depends also on the Lagrangian multiplier $\theta$ of the incentive compatibility constraint. The first-order condition for transfers under private information, Eq. 11, depends on the same quantities. Therefore, upon suitable parameterization of the distribution of income, these two equations could in principle be used to back out information about the counterfactual distribution of income associated with shirking.

In order to do so, we posit that income under high effort is lognormally distributed, with parameters $\left(\mu, \sigma^{2}\right)$. Further, we assume that low effort leads to a reduction in the mean of the income distribution to $\mu_{c}$, with $\mu_{c}<\mu .{ }^{21} \mathrm{We}$ set $\mu$ to the mean of permanent earnings, as reported in Altonji et al. (1996). The standard deviation of log earnings is obtained from Daly and Valetta (2003) and set to $\sigma=0.63$. After solving the first-order condition Eq. 11 for the multiplier $\theta$ and inserting the result into Eq. 12, we solve the latter for $\mu_{c}$.

Before reporting the estimates, we note that the value of $\lambda$ used in the previous computations was derived by setting the first-order condition with respect to transfers at equality, in the model of complete information. That is, given the magnitudes for $c_{p}$ and $c_{c}$ found in the data, $\lambda$ was a root to the relation

$$
\lambda u^{\prime}\left(c_{p}\right)=(1-\lambda) u^{\prime}\left(c_{c}\right),
$$

where separability of consumption and leisure is already incorporated. However, the first-order condition for transfers under private information, Eq. 11, is instead

$$
\lambda u^{\prime}\left(c_{p}\right)=u_{1}\left(c_{c}\right)\left[(1-\lambda)+\theta\left(1-F\left(I_{c}\right)\right)\right] .
$$

Therefore, if the value of $\lambda$ that solved Eq. 23 were used, it would force the multiplier $\theta$ to zero and/or set $\mu_{c}$ to equal $\mu$, so that $F\left(I_{c}\right)$ equaled unity. If a meaningful solution to the private information case is to be found, we must allow $\lambda$ to exceed the benchmark value selected under complete information. In what follows, we consider three values of $\lambda$, corresponding to 10, 20 and $30 \%$ increments over the full information benchmark. Given these values,

${ }^{21}$ It is straightforward to show that $F^{\prime}\left(I_{c}\right)<0$ obtains if $\mu_{c}<\mu$. 
Table 2 Redistributive neutrality under private information

Parameter values: $\alpha=-1$, $\mu=10.645, \sigma=0.63$

* Target value of the computations

\begin{tabular}{lrrr}
\hline$\lambda$ & 0.69 & 0.75 & 0.81 \\
$\theta$ & 2.51 & 1.70 & 1.53 \\
$\mu_{c}\left(I_{c} \mid \mu_{c}\right)$ & 10.47 & 10.33 & 10.23 \\
$\frac{E\left(I_{c} \mid \mu\right)}{\beta_{1}}$ & 83.56 & 72.94 & 65.94 \\
$\beta_{2}$ & 0.44 & 0.44 & 0.44 \\
$\left(\beta_{1}-\beta_{2}\right)^{*}$ & 0.31 & 0.31 & 0.31 \\
\hline
\end{tabular}

and using the consumption numbers from above (corresponding to average PSID values), we then look for values of $\mu_{c}$ that solve Eq. 12 once $\theta$ has been substituted out. Results are reported in Table $2 .{ }^{22}$

Given our assumption that income is lognormally distributed, its expected value when high effort is exerted equals $\exp \left(\mu+\sigma^{2} / 2\right)$. Thus, the ratio $\left(\exp \left(\mu_{c}\right) / \exp (\mu)\right) * 100$ measures the fraction of mean income associated with the distribution with low effort relative to mean income when high effort is exerted instead. This information is also included in Table 2 in the row labeled $\left(E\left(I_{c} \mid \mu_{c}\right) / E\left(I_{c} \mid \mu\right)\right) * 100$. The table also includes the figures obtained for $\beta_{1}$ and $\beta_{2}$ (in addition to their difference).

For the lowest value of $\lambda$, deviating only $10 \%$ from the benchmark case of the previous section, we find that mean income associated with the low effort distribution corresponds to $84 \%$ of mean income of the actual distribution of earnings, a sizable income reduction. Comparative statics with respect to $\lambda-$ given by columns 2 and 3 of Table 2 -show that $\mu_{c}$ decreases with $\lambda$, leaving mean income under low effort at only $66 \%$ of mean income under $\mu$ for the highest value of $\lambda$. The same comparative statics emerge when other values of $\alpha$ are considered. The size of the income reduction increases with $\alpha$. For $\alpha=0.5$, for example, the income reduction is more sizeable, ranging between 61 and $41 \%$ of mean income under $\mu$ (from lowest to highest $\lambda$ ). The table shows that $\beta_{2}$, the transfer derivative with respect to the child's income, is positive. This reflects the need to compensate for the child's diligence. The value of $\beta_{2}$ was found to be positive under all parameter combinations. The magnitude and sign of transfer derivatives - with respect to $I_{p}$ and $I_{c}$ - are virtually insensitive to different values of $\alpha$ and $\sigma$.

The results for $\mu_{c}$ vary negatively with $\sigma$ but they are very stable in this dimension. With $\alpha=-1$ and $\sigma=0.4$, for example, mean income under $\mu_{c}$ ranges between 84 and $69 \%$ of mean income under $\mu$; for $\sigma=0.8$, instead, the corresponding values range between 83 and $65 \%$. The same pattern emerged when other values of $\alpha$ were considered.

The logic presiding this quantitative exercise-taking an estimate of $T_{1}-T_{2}$ from the empirical literature and finding parameter values that would match that number-was also attempted in the previous section, under complete information. There, however, no set of parameter values could target the

\footnotetext{
${ }^{22}$ Results were obtained using Matlab's routine 'fsolve' and the code is available upon request. They were insensitive to initial conditions.
} 
empirical estimate of 13 cents found in Altonji et al. (1997) (complex values were found for $\omega$ and $\gamma$ in these cases).

Endogenous hours and private information Next, we examine the implications of endogenous hours as "measured" by the quantitative results of the previous section. The models of Sections 2 and 3 provide two independent forms of considering endogenous labor supply: endogenous hours and endogenous effort. Introspection readily suggests those two forms to be simultaneously at work and that income variation across households reflects both. Results from the previous section suggest that controlling for labor supply would have raised the benchmark for transfer derivatives to a number above unity. The computations for the benchmark case with $\alpha=-1$ put the difference $T_{1}-T_{2}$ at about 1.5. To take this into account, we repeat the computations of the derivative Eq. 12 to get a value for $\mu_{c}$ but now allowing the benchmark value for $T_{1}-T_{2}$ to exceed unity. If the empirical estimate of the transfer derivative difference is 13 cents, we solve

$$
0.13=\left(1+d-\frac{u_{1}\left(c_{c}, 1-e_{H}\right) \theta U_{1}\left(c_{c}\right) F^{\prime}\left(I_{c}\right)}{D}\right)
$$

for $\mu_{c}$, after using the first-order condition to eliminate $\theta$. Without the ability to adjust hours worked, $d$ should equal 0 ; with endogenous hours, our simulations suggest that $d$ is a positive number. ${ }^{23}$ We additionally perform sensitivity analysis by experimenting with different values of $d$. Results indicate that higher target values of the transfer derivative (higher $d$ ) raise the values obtained for $\mu_{c}$. For example, for $T_{1}-T_{2}=1.5(d=0.5)$, expected income under $\mu_{c}$ ranged between 89 and $75 \%$ of mean income under $\mu$. The corresponding figures for the case when the transfer derivative targeted 1.75 instead $(d=0.75)$ ranged between 91 and $79 \%$. Targeting 1.25 delivered a range for expected income under $\mu_{c}$ between 87 and $71 \%$ of mean income under $\mu$.

The magnitude of $\beta_{2}$, the simulated derivative of transfers with respect to the child's income, is sensitive to the benchmark value considered for $T_{1}-T_{2}$. When that benchmark is increased, $\beta_{2}$ increases and becomes even more positive. ${ }^{24}$ When $T_{1}-T_{2}$ is targeted at $1.25, \beta_{2}$ increases to 0.56 . When the target value of the derivative difference is 1.75 instead $(d=0.75), \beta_{2}$ increases further to 1.06. Therefore, our results suggest that incentives may cause the sign of the transfer derivative with respect to the child's income to be symmetric to that prevailing under "pure altruism" or to the one prevailing in situations where the incentive compatibility constraint does not bind.

${ }^{23}$ Previous computations in this section found a value for $\mu_{c}$ that solved instead

$$
0.13=\left(1-\frac{u_{1}\left(c_{c}, 1-e_{H}\right) \theta U_{1}\left(c_{c}\right) F^{\prime}\left(I_{c}\right)}{D}\right) .
$$

\footnotetext{
${ }^{24}$ The values obtained for $\beta_{1}$ do not vary with $d$ and, as predicted by the model, that derivative is positive under all parameter configurations considered.
} 


\subsection{Discussion}

Tests of the altruism model have generally rejected the neutrality result as very low magnitudes for the transfer derivative difference are customarily obtained (see Laferrère and Wolff (2006) for a revision of empirical work on altruism). The first computation of this difference was performed by Cox and Rank (1992), but many other examples followed suit. See, e.g., Altonji et al. (1997), McGarry and Schoeni $(1995,1997)$, for American data, but also Wolff (2000), for French data, and Jürges (1999), in Germany. Some evidence for developing countries suggests that, in environments where public transfers are much more limited in size and scope, more direct evidence about altruism or other transfer motives might be uncovered. This is the case, for example, in Cox et al. (2004) using data from the Philippines, where the transfer derivative test is met with success when the recipient's income is below a given threshold. Raut and Tran (2005) also find evidence of altruism using Indonesian data.

The predictions of altruism are not of course limited to the derivative test but they also concern-among other implications-the sign of the response of transferred quantities with respect to the donor and recipient's income. "Pure" altruism predicts transfers to be compensatory, increasing in the donor's income and decreasing in the recipient's. Results are also mixed here, with Cox and Raines (1985), Cox (1987), and Cox and Rank (1992) finding a positive relationship between amounts received and recipient's income. However, it is perhaps fare to say that the bulk of the evidence favors a compensatory nature for financial transfers, with amounts going disproportionately from richer to poorer family members and transfers found to respond to income with the signs predicted by altruism. This is the case in Altonji et al.'s $(1996,1997)$ work, McGarry and Schoeni $(1995,1997)$, and many others. Further, time transfers also do not appear to be exchanged for money transfers (Altonji et al. (1996) and Ioannides and Kan (2000), the latter also examining financial transfers). The overall view regarding altruism is thus one where the more extreme result of neutrality fails to find empirical support but where the compensatory nature of financial transfers and the independence between monetary and time transfers is broadly supported by data, if not everywhere. As Arrondel and Masson put it, to reconcile empirical findings with altruism we need "a model with an altruistic component that leads, nevertheless, to small compensatory effects of transfers" (Arrondel and Masson 2006, pp:1005). The model of incomplete information provides an answer to this quest. While quantitatively the predictions of the endogenous hours model were ambiguous regarding the derivative difference, the model under incomplete information predicts that derivative differences should be strictly lower than unity, exactly what is needed to reconcile empirical findings and altruism. Further, the quantitative results above suggest that the model under incomplete information is capable of fitting the data even when the endogenous choice of hours is considered.

The results under private information suggest that asymmetries of information play an important quantitative role as the reduction in expected income associated with low effort is nontrivial. If children chose to shirk, their income 
would be drawn from a distribution whose mean is only $84 \%$ of the mean income they would attain instead by working hard, for the benchmark case; this mean income reduction can be significantly more substantive for other parameter configurations, reaching values as low as $66 \%$ in some cases. Results under private information were found to be sensitive to the endogenous hours benchmark for the transfer derivative difference, with smaller income reductions under low effort associated with higher values of the $T_{1}-T_{2}$ difference.

The results in this paper suggest that empirical testing be directed at assessing the relevance of private information within the family. Villanueva (2007) finds that the extended family appears to insulate the child's consumption from declining when either the child or the spouse report a "physical/nervous condition that limits amount of work." When no family fixed effects are considered, the reduction in consumption in the child's household is 2 to 3 times greater relative to when those fixed effects are included (see Table 6 of Villanueva 2007). ${ }^{25}$ A disabling health condition is likely observable by the parent, at least in part. Thus, income losses experienced during illness should be less prone to the inference problem associated with private information and shirking: the parent is likely to accept these as beyond the control and effort of the child, and as being truly exogenous. Therefore, we would expect the parent to willingly compensate a greater fraction of those losses relative to income reductions of a general nature, as appears to be the case in the data. ${ }^{26}$

At a deeper level, this paper questions the legitimacy of testing the original concept of Ricardian Equivalence, based on lump-sum intergenerational redistribution, from the kind of income variation that is obtainable from cross-sectional data, where endogenous effort in (at least) two complementary dimensions is present and which has predictions differing from those of Ricardian Equivalence. Clearly, income variation across households cannot be considered "lump-sum ." Testing Ricardian Equivalence would require finding a natural experiment such as an unexpected change in tax law, or comparing the effects of income changes across different income categories

\footnotetext{
${ }^{25}$ Included in the prediction of altruism is the fact that consumption of individual households within the extended family linked by positive transfers should commove perfectly and individual income of a particular household should not have a differentiated effect on that household's consumption relative to that of other households in the family. This is yet another face of the redistributive neutrality result. The first test of this prediction was carried out by Altonji et al. (1992).

${ }^{26}$ Villanueva conceptualizes the child's household as having two earners, primary and secondary, and posits that the latter is the only one with an elastic labor supply. He assumes that parents can observe the earnings of both children but not the wages received by the secondary earner. Simulations of the model indicate that parental transfers will compensate a larger fraction of an income loss suffered by the primary earner compared to the secondary earner. He also tests empirically how parental transfers respond to the earnings of both earners and finds the same pattern in the data. Since the secondary earner is also - by assumption - the earner with greater labor supply wage elasticity, and his simulations under complete information show that parents also respond less to income losses of that earner, it is not clear how much of the differential response of transfers is due to private information or simply to hourly adjustment to wage changes.
} 
and situations. For example, a parent might compensate a greater fraction of income loss following the event "my child's house burned down" relative to an equal size reduction in permanent income whose cause is not well established. While finding a fitting income category or a situation that would correspond to lump-sum redistribution is a challenging task, it would appear to be the only legitimate way of testing Ricardian Equivalence and altruism.

\section{Conclusion}

This paper has extended the basic model of altruism to include two complementary dimensions of labor supply: endogenous hours and endogenous effort. The explicit inclusion of labor supply allows us to differentiate the parental transfer response to exogenous income variation-driven by events beyond the control of the child-and which embodies the lump-sum notion of income redistribution associated with Ricardian Equivalence, from the transfer response to income changes that are driven by wage changes and effort. Endogenous labor supply shows that one should not expect parental transfers to offset income redistribution within the family unless we could control for wages and/or hours worked, and for private information. It thus contradicts the premise of a large body of empirical work that the lack of a unitary difference in transfer derivatives would be a negation of altruism.

The quantitative results provided suggest that endogenous labor supply is responsible for sizable deviations from the unitary transfer derivative benchmark that goes with lump-sum income redistribution. We see the results in this paper-both theoretical and quantitative — as a challenge to future research on the family and on the motives underlying intra-family transfers.

Acknowledgements I am grateful to Robert E. Lucas, Jr., Fernando Alvarez, Gary S. Becker, Sherwin Rosen and Pedro Mira for comments, and also for valuable suggestions by two anonymous referees. Financial support from Banco de Portugal, Fundação para a Ciência e a Tecnologia and Fundación Ramón Areces is very gratefully acknowledged.

\section{References}

Altonji JG, Hayashi F, Kotlikoff LJ (1992) Is the extended family altruistically linked? direct tests using micro data. Am Econ Rev 82(5):1177-1198

Altonji JG, Hayashi F, Kotlikoff LJ (1996) The effects of income and wealth on time and money transfers between parents and children. Working Paper no 5522, Cambridge, Mass, NBER

Altonji JG, Hayashi F, Kotlikoff LJ (1997) Parental altruism and inter vivos transfers: theory and evidence. J Polit Econ 105(6):1121-1166

Arrondel L, Masson A (2006) Altruism, exchange or indirect reciprocity: what do the data on family tranfers show? In: Kolm S, Ythier JM (eds) Handbook of the economics of giving, altruism and reciprocity, vol 2. North-Holland, Amsterdam, pp 971-1053

Barro RJ (1974) Are government bonds net wealth? J Polit Econ 82(6):1095-1117

Becker GS (1974) A theory of social interactions. J Polit Econ 82(6):1063-1093

Bernheim BD, Shleifer A, Summers LH (1985) The strategic bequest motive. J Polit Econ 93(6):1045-1076 
Blundell R, Duncan A, Meghir C (1998) Estimating labor supply responses using tax reforms. Econometrica 66(4):827-861

Borjas GJ (1996) Labor economics. McGraw-Hill

Bruhin A, Winkelmann R (2009) Happiness functions with preference interdependence and heterogeneity: the case of altruism within the family. J Popul Econ 22(4):1063-1080

Chami R (1996) King Lear's dilemma: precommitment versus the last word. Econ Lett 52(2): 171-176

Chami R (1998) Private income transfers and market incentives. Economica 65(260):557-580

Cigno A (1993) Intergenerational transfers without altruism: family, market and state. Eur J Polit Econ 9(4):505-518

Cigno A (2000) Saving, fertility and social security in the presence of self-enforcing intra-family deals. In: Mason A, Tapinos G (eds) Sharing the wealth. Oxford University Press, New York, pp 232-255

Cigno A (2006) The political economy of intergenerational cooperation. In: Kolm S, Ythier JM (eds) Handbook of the economics of giving, altruism and reciprocity, vol 2. North-Holland, The Netherlands, pp 1505-1558

Cigno A, Giannelli GC, Rosatti F (1998) Voluntary transfers among italian households: altruistic and nonaltruistic explanations. Struct Chang Econ Dyn 9(4):435-451

Cigno A, Giannelli GC, Rosatti F, Vuri D (2006) Is there such a thing as a family constitution? A test based on credit rationing. Rev Econ Household 4(3):183-204

Cox D (1987) Motives for private income transfers. J Polit Econ 95(3):508-546

Cox D, Hansen BE, Jimenez E (2004) How responsive are transfers to income? Evidence from a laissez-faire economy. J. Public Econ. 88(9-10):2193-2219

Cox D, Raines F (1985) Interfamily transfers and income redistribution. In: David M, Smeeding T (eds) Horizontal equity, uncertainty and economic well-being. NBER and University of Chicago Press, United States of America pp 393-426

Cox D, Rank M (1992) Inter-vivos transfers and intergenerational exchange. Rev Econ Stat 74(2):305-314

Daly M, Valetta R (2003) Earnings inequality and earnings mobility in the US. Federal Reserve Bank of San Francisco Economic Letter 28

Dustmann C, Micklewright J (2001) Intra-household transfers and the part-time work of children. CEPR Discussion Paper 2796

Fernandes A (1999) Familial preferences and economic choices: does distribution matter? University of Chicago Dissertation

Fernandes A (2000) Altruism with endogenous labor supply. CEMFI Working Paper 0002

Gatti R (1997) Family altruism and incentives. Mimeo, Harvard University

Hirshleifer J (1977) Shakespeare versus Becker on altruism: the importance of having the last word. J Econ Lit 15(2):500-502

Holtz-Eakin D, Joulfaian D, Rosen HS (1993) The carnegie conjecture: some empirical evidence. Q J Econ 108(2):413-435

Ioannides Y, Kan K (2000) The nature of two-directional intergenerational transfers of money and time: an empirical analysis. In: Ǵérard-Varet LA, Kolm SC, Ythier JM (eds) The economics of reciprocity, gift-giving and altruism. MacMillan Press, London, pp 314-331

Joulfaian D, Wilhelm MO (1994) Inheritance and labor supply. J Hum Resour 29(4):1205-1234

Jürges H (1999) Parent-child transfers in Germany: a study of magnitude and motivations. Z Wirtsch Socialwiss 119(3):429-453

Laferrère A, Wolff FC (2006) Microeconomic models of family transfers. In: Kolm S, Ythier JM (eds) Handbook of the economics of giving, altruism and reciprocity, vol 2. North-Holland, Amsterdam, pp 889-969

McGarry K (2000) Testing parental altruism: implications of a dynamic model. NBER WP 7593

McGarry K, Schoeni R (1995) Transfer behavior in the health and retirement survey: measurement and the redistribution of resources within the family. J Hum Resour 30(5):184-226

McGarry K, Schoeni R (1997) Transfer behavior within the family: results from the asset and health retirement survey. J Gerontol 52B(Special Issue):82-92

Raut LK, Tran LH (2005) Parental human capital investment and old-age transfers from children: is it a loan contract or reciprocity for Indonesian families? J Dev Econ 77(2):389-414 
Schwarze J, Winkelmann R (2005) What can happiness research tell us about altruism? evidence from the German socio-economic panel. IZA Discussion Papers 1487

Sloan FA, Zhang HH, Wang J (2002) Upstream intergenerational transfers. South Econ J 69(2):363-380

Villanueva E (2007) Parental altruism under imperfect information: theory and evidence. Mimeo

Wolff FC (1998) Altruisme, échange et réciprocité. Les transferts inter vivos entre deux et entre trois générations, $\mathrm{Ph}$. Dissertation, University of Nantes

Wolff FC (2000) Transferts Monetaires inter vivos et Cycle de Vie. Rev écon 51(6):1419-1452

Wolff FC (2006) Parental transfers and the labor supply of children. J Popul Econ 19(4):853-877 